\title{
A label-free, novel electrofluidic capacitor biosensor for Prostaglandin E2 detection towards early and rapid Urinary Tract Infection diagnosis
}

Antra Ganguly ${ }^{1}$, Tahmineh Ebrahimzadeh ${ }^{2}$, Philippe Zimmern ${ }^{3}$, Nicole J De Nisco ${ }^{2}$, and Shalini Prasad ${ }^{1 *}$

${ }^{1}$ Department of Bioengineering, University of Texas at Dallas, Richardson, TX 75080, USA

${ }^{2}$ Department of Biological Sciences, University of Texas at Dallas, Richardson, TX 75080, USA

${ }^{3}$ Department of Urology, University of Texas Southwestern Medical Center, Dallas, TX 75390, USA

${ }^{*}$ Corresponding author email: Shalini.Prasad@utdallas.edu. 
Table S1. List of current methods of UTI detection

\begin{tabular}{|c|c|c|c|c|c|}
\hline Technique & Detection method & Analysis time & $\begin{array}{l}\text { Culture } \\
\text { based? }\end{array}$ & $\begin{array}{l}\text { Portability or } \\
\text { POC } \\
\text { Capability? }\end{array}$ & Comments \\
\hline Lab culture test & Microscopy & 24-72 hours & Yes & No & $\begin{array}{l}\text { Gold standard, } 30-50 \% \\
\text { diagnostic error rates }\end{array}$ \\
\hline MALDI-TOF & $\begin{array}{l}\text { Mass } \\
\text { spectrometry }\end{array}$ & $\begin{array}{l}4-6 \text { hours after } \\
\text { culturing }\end{array}$ & Yes & No & $\begin{array}{l}\text { High throughput but } \\
\text { requires large footprints, } \\
\text { expensive }\end{array}$ \\
\hline $\begin{array}{l}\text { Rapid FISH } \\
\text { (hemoFISH, } \\
\text { QuickFISH) }\end{array}$ & $\begin{array}{l}\text { Fluorescence in } \\
\text { situ hybridization }\end{array}$ & $\begin{array}{l}20 \text { minutes } \\
\text { after culturing }\end{array}$ & Yes & No & $\begin{array}{l}\text { Rapid, accurate but } \\
\text { translation to POC is } \\
\text { challenging }\end{array}$ \\
\hline SeptiFast & $\begin{array}{l}\text { Real-time } \\
\text { Polymerase Chain } \\
\text { Reaction }\end{array}$ & $\begin{array}{l}30 \text { minutes } \\
\text { after culturing }\end{array}$ & Yes & No & $\begin{array}{l}\text { Fast and multiplexed } \\
\text { analysis but culture } \\
\text { based }\end{array}$ \\
\hline $\begin{array}{l}\text { Real-time } \\
\text { microscopy }\end{array}$ & Microscopy & 24-36 hours & Yes & No & $\begin{array}{l}\text { Fast but culture based, } \\
\text { limited by breadth of } \\
\text { pathogen }\end{array}$ \\
\hline $\begin{array}{l}\text { Culture based } \\
\text { urine POC }\end{array}$ & $\begin{array}{l}\text { Optical, } \\
\text { electrochemical }\end{array}$ & 24-36 hours & Yes & Yes & Fast but culture based \\
\hline $\begin{array}{l}\text { Nitrite and } \\
\text { leukocyte } \\
\text { esterase } \\
\text { dipsticks }\end{array}$ & Colorimetric & 5 minutes & No & Yes & $\begin{array}{l}\text { Low sensitivity and poor } \\
\text { resolution }\end{array}$ \\
\hline $\begin{array}{l}\text { Electrofluidic } \\
\text { capacitor based } \\
\text { PGE2 biosensor }\end{array}$ & Electrochemical & 5 minutes & No & Yes & This work \\
\hline
\end{tabular}


Figure S1. Schematic describing the inputs and outputs of the proposed electrofluidic capacitor system

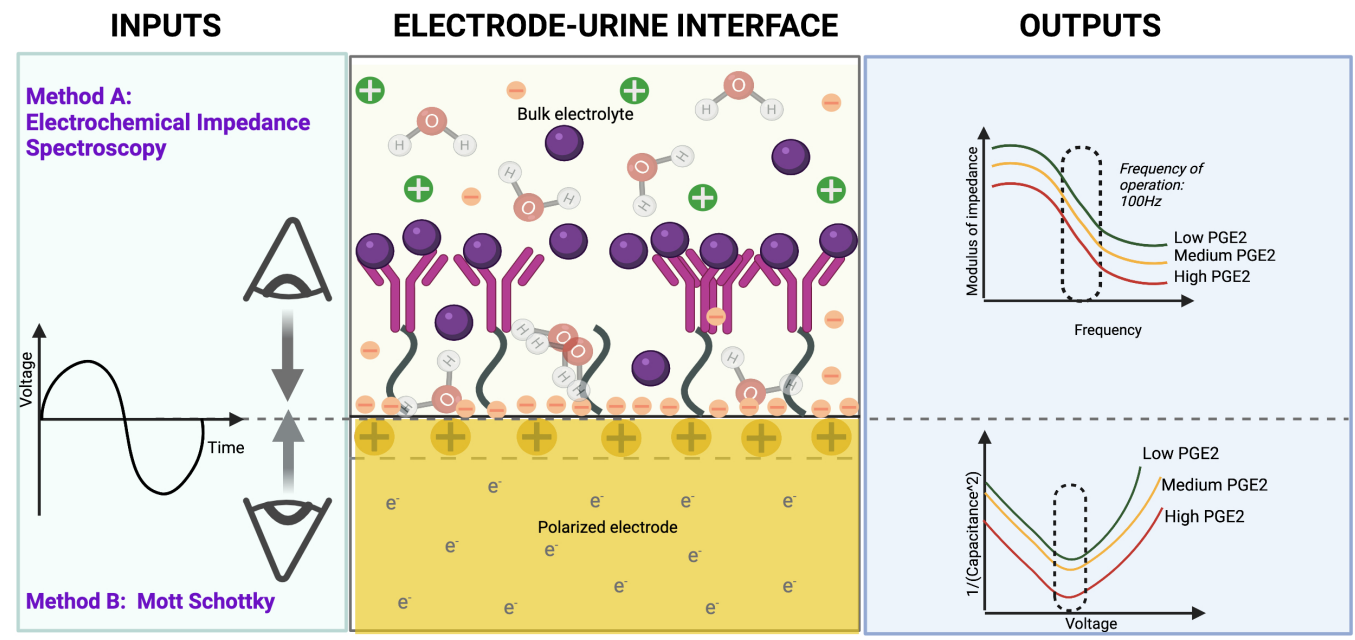

Figure S2. Antibody saturation studies to identify the antibody loading capacity at the working electrode

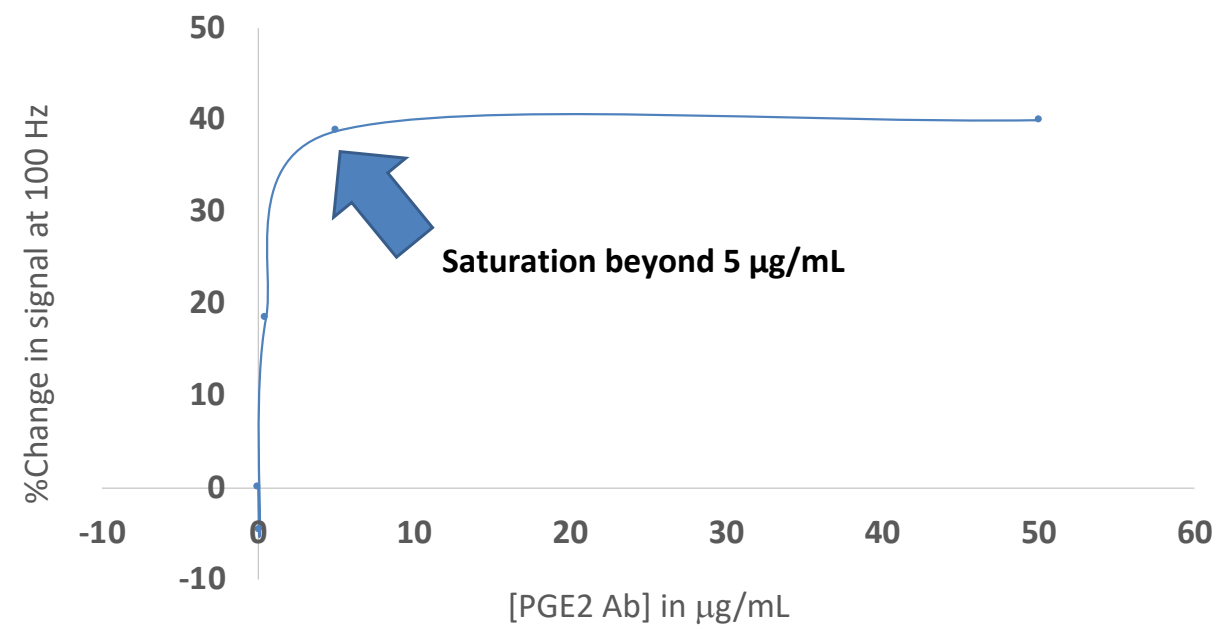

Figure S3. Analysis bulk effects on electrochemical performance for Chronoamperometry and Chronocoulometry experiments. 

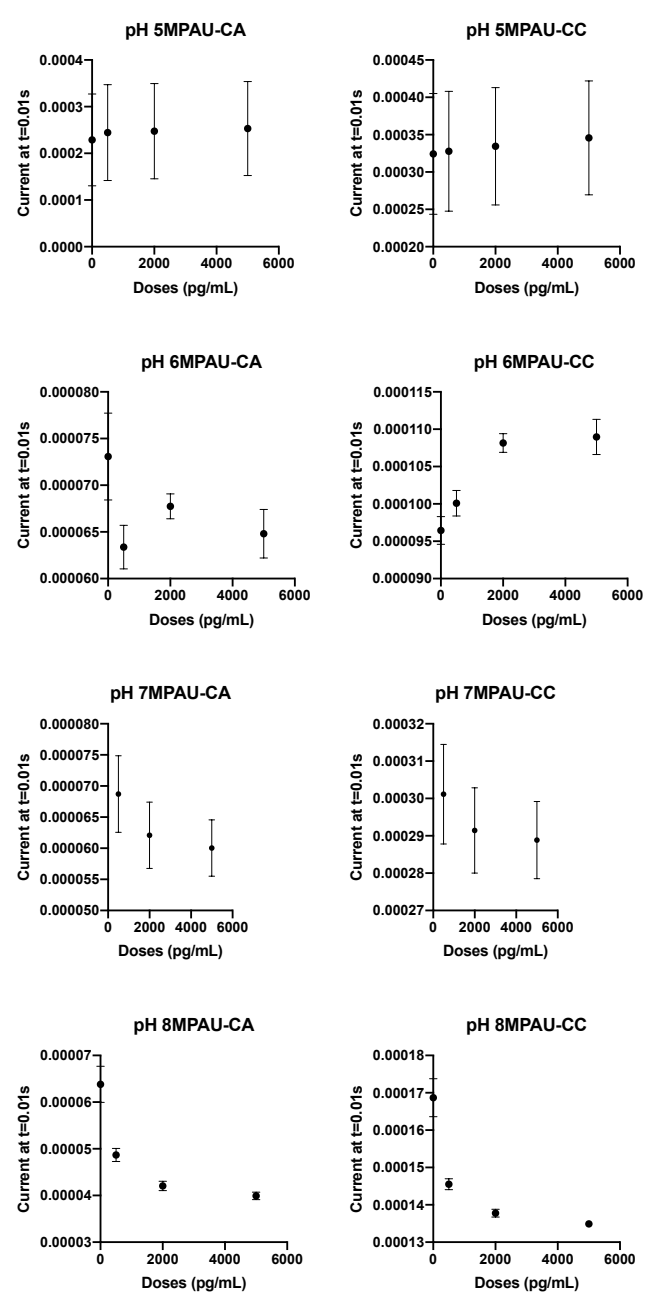

Figure S4. Surface Plasmon Resonance based validation of PGE2 Antibody-antigen binding

\section{Surface Plasmon Resonance}

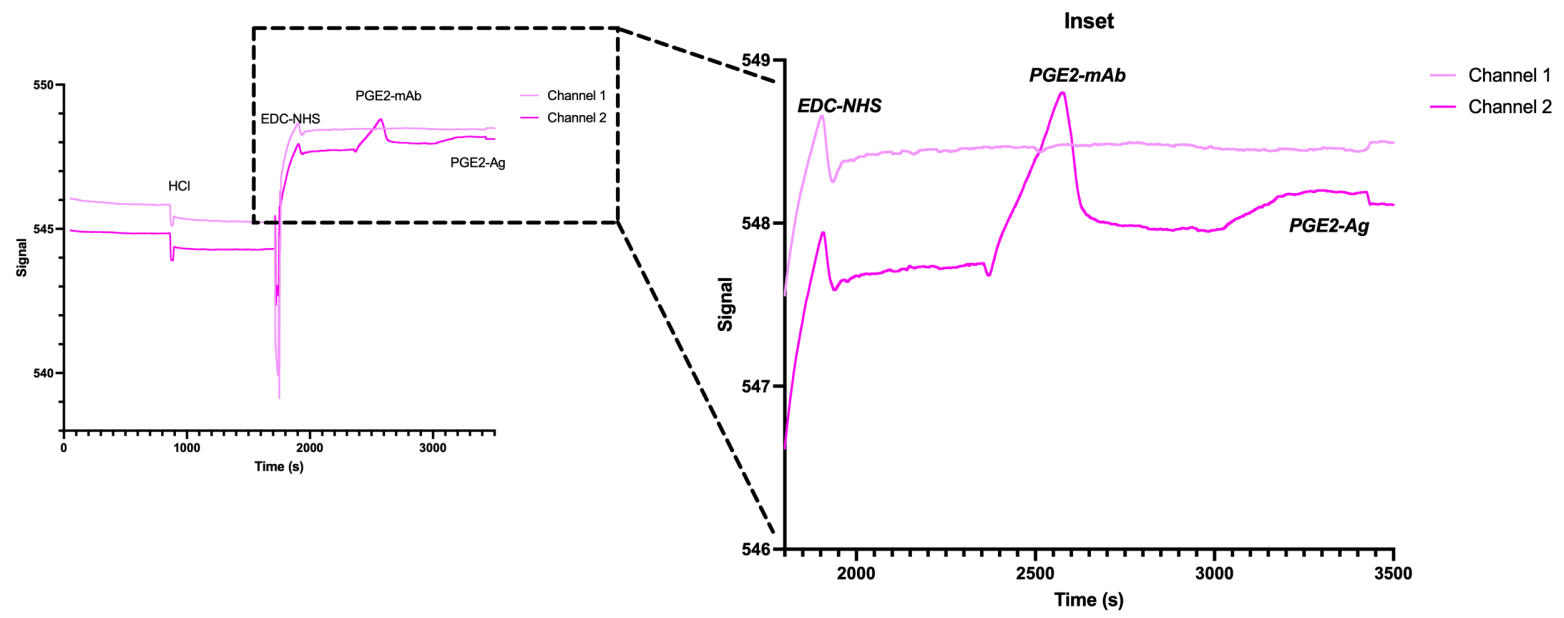


Figure S5. Calibration dose-response in artificial urine (pH 6) for low, medium and elevated PGE2 levels for EIS and MS. Statistical significance was achieved using 1-way ANOVA $(\alpha=0.05)$.

Electrochemical Impedance Spectroscopy

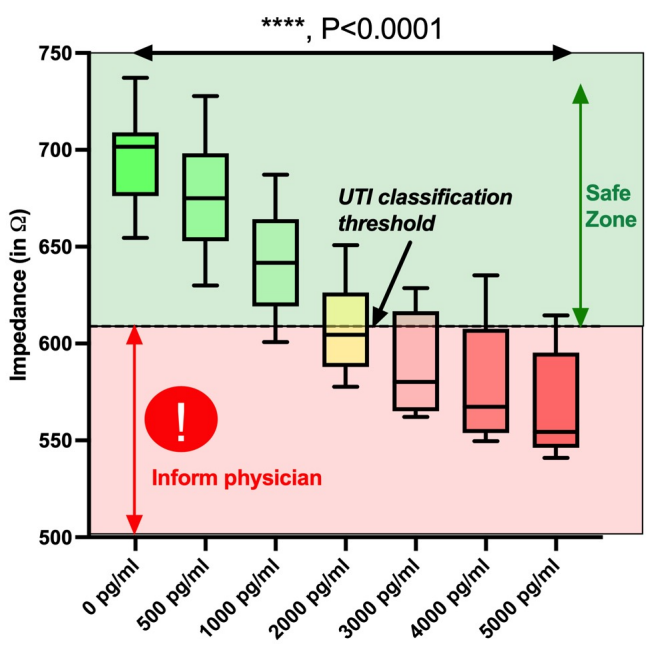

PGE2 concentration (pg/mL)
Mott Schottky

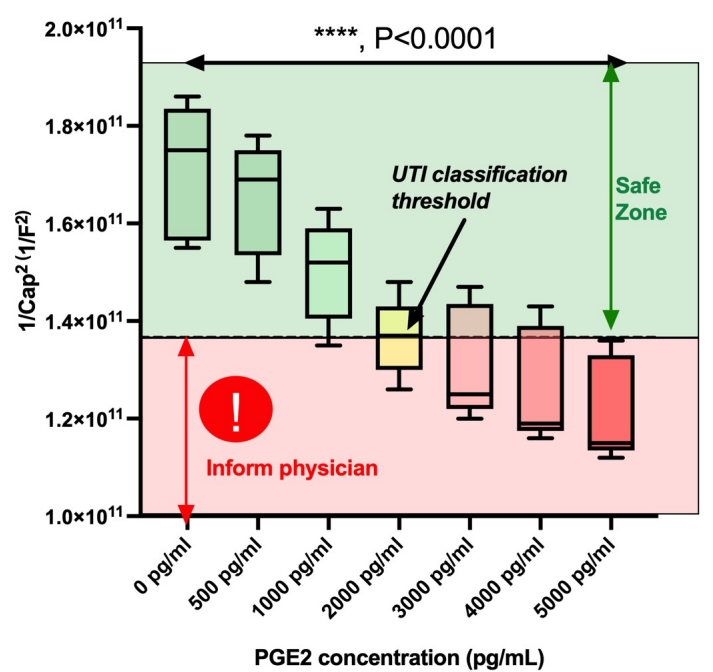


Figure S6. Evaluation of the effect of urine pH using EIS (A-D) and MS (E-H) on the performance of the electrofluidic urine biosensor

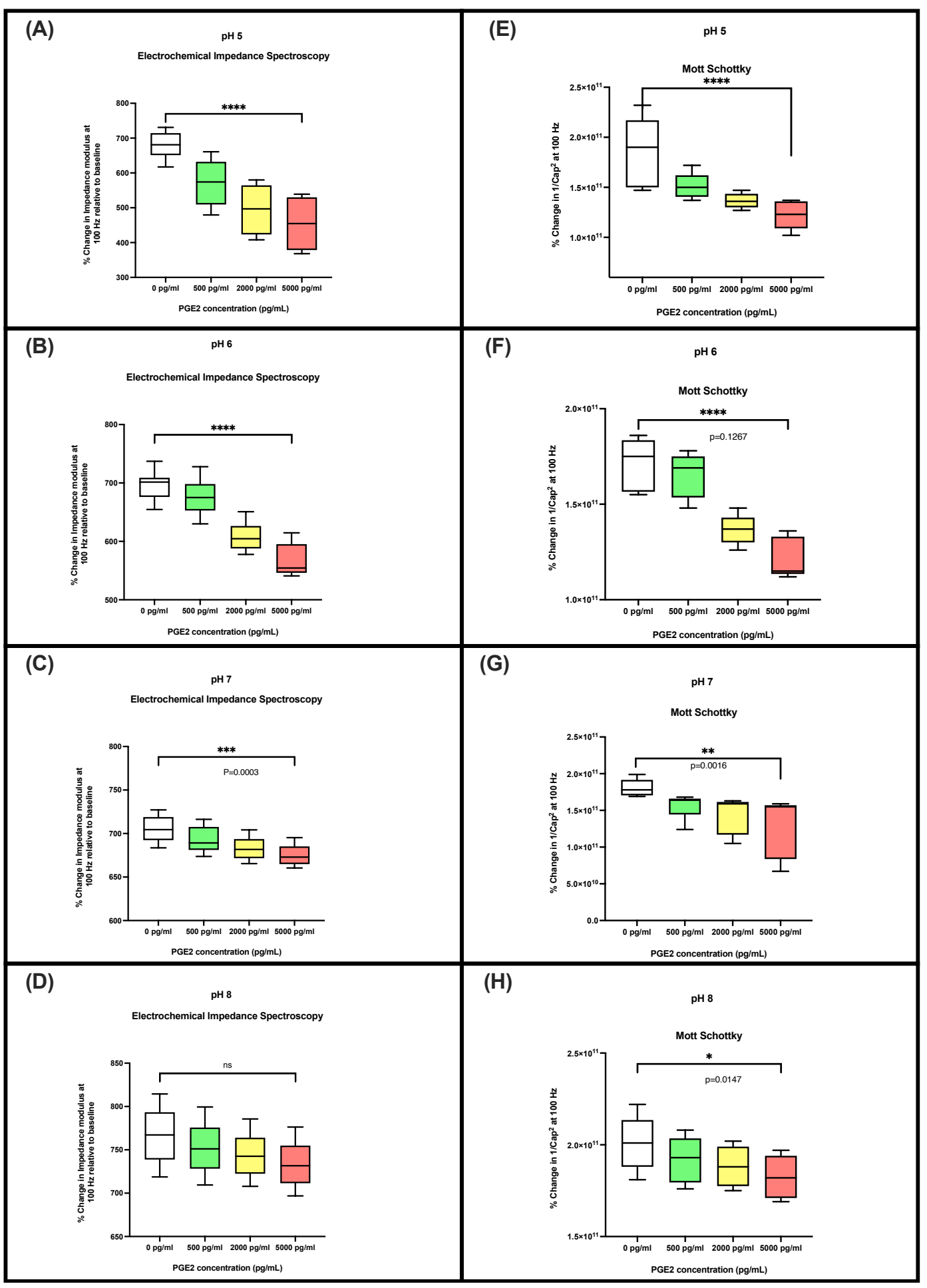


Figure S7. Calibration dose-response in pooled human urine for low, medium and elevated PGE2 levels for EIS and MS. Statistical significance was achieved using 1-way ANOVA $(\alpha=0.05)$.
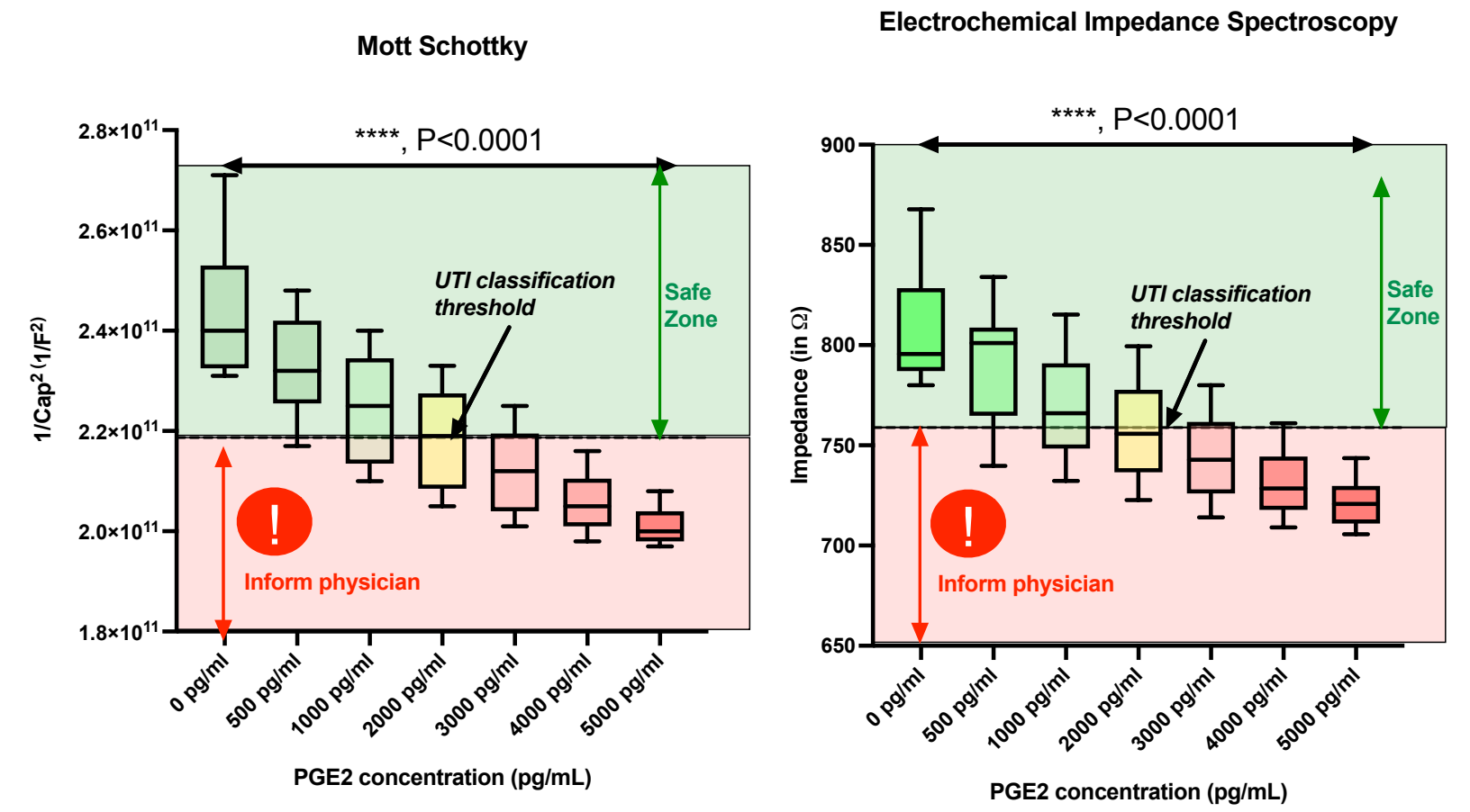

The percent change values for different doses in the calibration dose response for pooled human urine studies (shown in Figure 4) were calculated relative to the zero-dose value (EIS and MS response to zero dose/ baseline dose i.e., $0 \mathrm{pg} / \mathrm{mL}$ of PGE2 in un-spiked/raw) in the pooled human urine sample. The percent changes were calculated based on the following formula:

For EIS, Percentage change in modulus of impedance at $100 \mathrm{~Hz}=$

$100 *$ (baseline value of modulus of impedance - spiked PGE2 dose value of modulus of impedance baseline value of modulus of impedance

For MS, Percentage change in 1/Capacitance 2 at $100 \mathrm{~Hz}=$

$\frac{100 *\left(\text { baseline value of } 1 / \text { Capacitance }{ }^{\wedge} 2-\text { spiked PGE } 2 \text { dose value of } 1 / \text { Capacitance }^{\wedge} 2\right)}{\text { baseline value of } 1 / \text { Capacitance }{ }^{\wedge} 2}$ 
Figure S8. Effect of buffer matrix on the sensor detection limits for EIS and MS
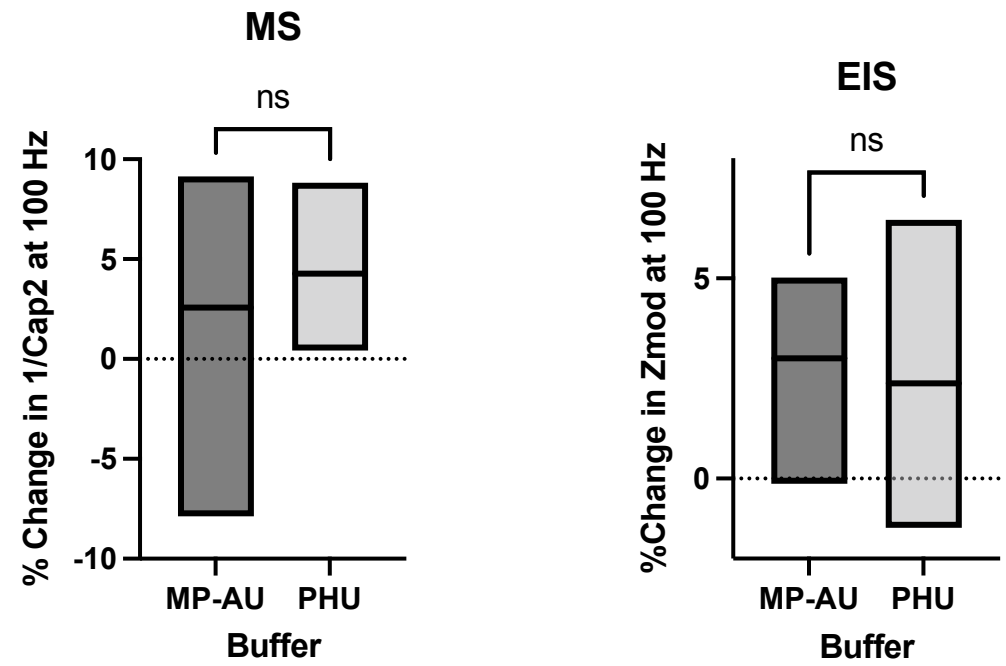

To test for the matrix effect of the ionic buffer on the detection limit of the sensor, the sensor response to the lowest dose (i.e., $500 \mathrm{pg} / \mathrm{mL}$ of PGE2) spiked in the artificially prepared urine (MP-AU) and the commercially obtained pooled human urine (PHU) samples were compared. The responses were measured as the percent change in the signal response relative to the corresponding baseline/ zero doses of the buffers (i.e., MP-AU and PHU) for both EIS and MS.

As shown in the figure below, using unpaired t-test, $\alpha=0.05(n=9)$, it was found that no significant difference exists in the signal response for for MP-AU versus PHU for MS ( $\mathrm{p}=$ $0.6095)$ and EIS $(p=0.5532)$. In this way, it was concluded that the detection limit of the sensor is not affected by the surrounding buffer matrix.

\section{Figure S9. Analysis of sensor response for EIS and MS experiments}

The figure below shows the characteristic plots for EIS measurements (represented as Nyquist plot) and Mott Schottky experiments (represented as Mott-Schottky plot showing $1 / \mathrm{C}^{\wedge} 2$ as a function of potential) for the pooled human urine studies).

The insets for both the plots show a dose dependent response to the wide dynamic range of the sensor which covers the physiologically relevant range of PGE2 in human urine. 


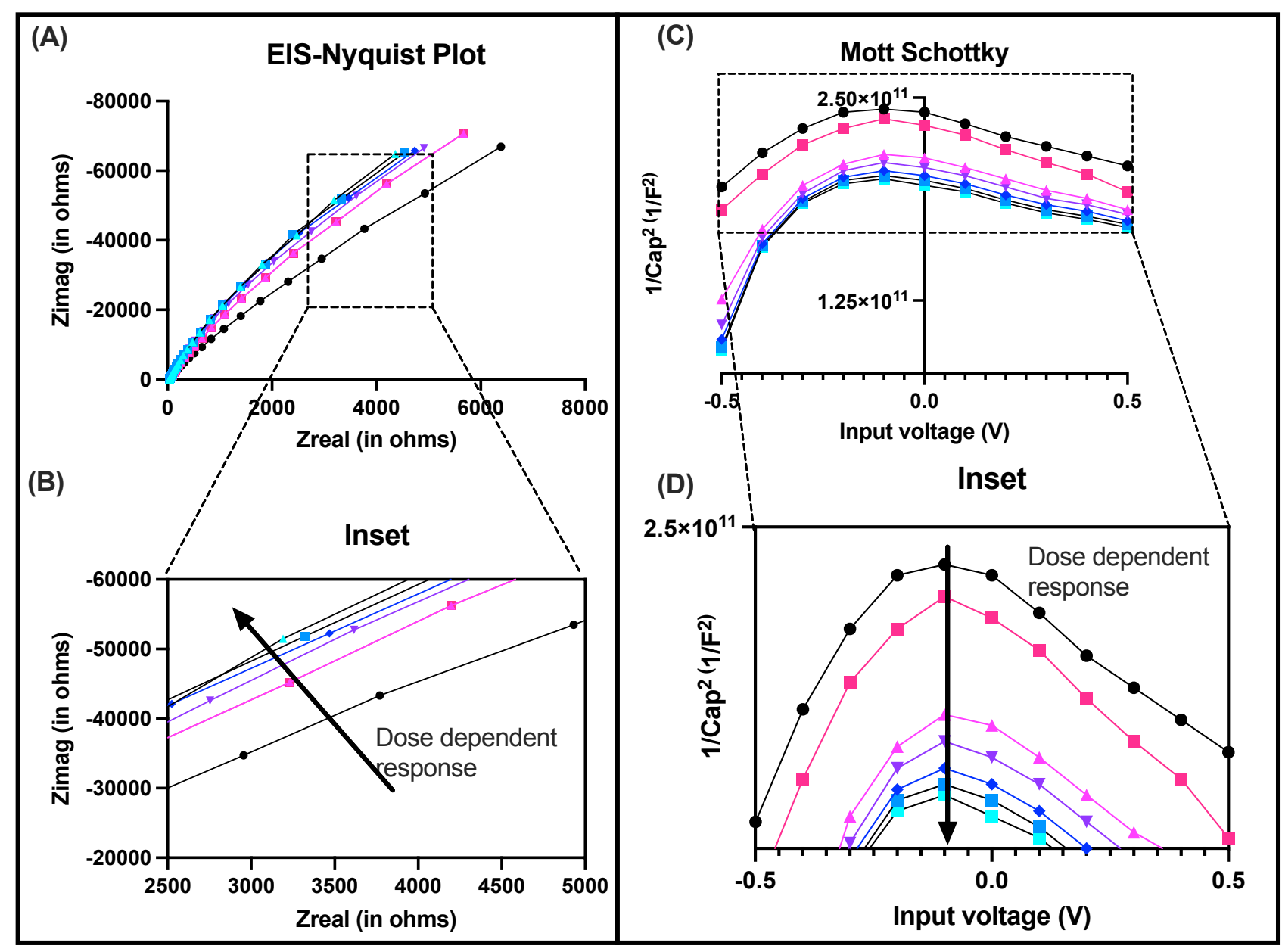

Legend:
- Zero Dose
- $500 \mathrm{pg} / \mathrm{mL}$
- $1000 \mathrm{pg} / \mathrm{mL}$
$\rightarrow 2000 \mathrm{pg} / \mathrm{mL}$
$\rightarrow 3000 \mathrm{pg} / \mathrm{mL}$
- $4000 \mathrm{pg} / \mathrm{mL}$
-1- $5000 \mathrm{pg} / \mathrm{mL}$ 